\title{
Field Survey of Glycyrrhiza Plants in Central Asia (1). Characterization of $G$. uralensis, G. glabra and the Putative Intermediate Collected in Kazakhstan
}

\author{
Hiroaki Hayashi, ${ }^{* a}$ Sayaka Hattori, ${ }^{a}$ Kenichiro Inoue, ${ }^{a}$ Kanat Sarsenbaev, ${ }^{b}$ Michiho Ito, ${ }^{c}$ and \\ Gisho $\operatorname{HONDA}^{c}$ \\ ${ }^{a}$ Gifu Pharmaceutical University; 5-6-1 Mitahora-higashi, Gifu 502-8585, Japan: ${ }^{b}$ Institute of Botany and \\ Phytointroduction; Almaty, The Republic of Kazakhstan: and ${ }^{c}$ Graduate School of Pharmaceutical Sciences, Kyoto \\ University; Sakyo-ku, Kyoto 606-8501, Japan. Received January 7, 2003; accepted February 24, 2003
}

\begin{abstract}
The characteristics of Glycyrrhiza plants from 12 collection sites in southeasten Kazakhstan were investigated. G. uralensis was observed at 9 of the sites from Almaty to Shu, and G. glabra was observed at 8 sites. At 4 sites near Shu, and 1 site near Almaty, G. glabra and G. uralensis grew together forming a mixed population, and intermediate-type plants between them were also observed at 3 sites. Although two nucleotide substitutions of the chloroplast $r b c L$ gene were observed between $G$. uralensis and $G$. glabra, rbcL sequences of the intermediatetypes were divided into G. uralensis-type (G-A type) and G. glabra-type (A-T type). HPLC analysis of the roots indicated that species-specific flavonoids, glabridin and glycycoumarin, were detected in the roots of G. glabra and $G$. uralensis, respectively, but neither flavonoid was detected in underground parts of the intermediate-types. HPLC analysis of their leaves indicated a significant difference among $G$. uralensis, G. glabra and the intermediate-type plants. Both $G$. glabra-specific and $G$. uralensis-specific compounds were detected in the leaves of the intermediate-type, thus suggesting that the intermediate plants are hybrids of G. glabra and G. uralensis.
\end{abstract}

Key words licorice; Glycyrrhiza uralensis; Glycyrrhiza glabra; species-specific flavonoid

Licorice is one of the most important crude drugs in the world, and its major sweet constituent, glycyrrhizin (GL), is used in large quantities as a well-known natural sweetener and as a pharmaceutical. ${ }^{1,2)}$ Two Glycyrrhiza species, $G$. glabra and G. uralensis, are known as major GL-producing species, but their distribution in the world is different. ${ }^{2)} G$. glabra is found in Spain, Italy, Turkey, the Caucasus, Central Asia and the western part of China, whereas the distribution area of $G$. uralensis is from Central Asia to China. In addition to these two species, G. inflata, another GL-producing species, is found in the western part of China.

Extensive chemical studies revealed that licorice roots contain many saponins and flavonoids, along with GL. ${ }^{2,3)}$ In addition, many species-specific flavonoids, such as glabridin (GB) for G. glabra and glycycoumarin (GC) for G. uralensis, were detected in the underground parts of respective Glycyrrhiza species. $^{3-7)}$ Variation in flavonoid contents in leaves of G. glabra was also reported. ${ }^{8,9)}$ These variations in roots and leaves are very useful to identify the species of plant materials, but their relationships between morphological ${ }^{10,11)}$ and chemical ${ }^{3-9)}$ characteristics have not yet been elucidated in detail. ${ }^{6}$

Both G. glabra and G. uralensis are distributed in Central Asia as well as in the western region of China, ${ }^{2,10)}$ and both plants are capable of generating hybrids, ${ }^{12)}$ although their chemical characteristics were not reported. Thus, in order to compare the morphological and chemical characteristics of Glycyrrhiza plants, a field survey of these plants was performed in Kazakhstan, one of the countries of Central Asia.

\section{MATERIALS AND METHODS}

Plant Materials Underground parts, leaves and seeds of Glycyrrhiza plants used in the present study were collected in Kazakhstan in August, 2001, as shown in Fig. 1 and Table 1.
Chemicals Authentic samples of GL, GB and GC were obtained from Maruzen Pharmaceuticals, Japan. Isoquercitrin (IQ) and rutin (RT) were purchased from Extrasynthese, France. Pinocembrin (PN) and licoflavanone (LF) were isolated from the leaves of G. glabra. ${ }^{13)}$

Amplification and Sequencing of $\boldsymbol{r} \boldsymbol{b} \boldsymbol{c} \boldsymbol{L}$ Gene DNA was extracted from dry leaves by the cetyltrimethylammonium bromide (CTAB) DNA extraction method as reported previously. ${ }^{14)}$ The 240-bp DNA fragment covering the two nucleotide substitutions in the $r b c L$ gene between G. glabra and G. uralensis ${ }^{6}$ was amplified by the polymerase chain reaction (PCR) using the template DNA from leaves, Taq-DNA polymerase (Takara), anti-Taq high (Toyobo) and two primers, 5'-TTTATGCGTTGGAGAGACCG-3' and 5'-AAGTAGACCATTATCTCGGC-3'. After initial denaturation (2 min at $\left.95^{\circ} \mathrm{C}\right), 30$ cycles of $30 \mathrm{~s}$ at $95^{\circ} \mathrm{C}, 30 \mathrm{~s}$ at $55^{\circ} \mathrm{C}$ and $1 \mathrm{~min}$ at $72^{\circ} \mathrm{C}$ were performed on a thermocycler. The amplified fragment was treated with ExoSAP-IT (Amersham Pharmacia Biotech) to remove primers. The purified fragments were sequenced directly by the dideoxy chain termination method using a model 373A DNA sequencer (PE Biosystems).

HPLC Analysis of Roots and Leaves Dried plant samples were powdered with a mortar and pestle, and then 200 $\mathrm{mg}$ of each powdered sample was extracted with $5 \mathrm{ml}$ of $80 \%$ methanol at $60^{\circ} \mathrm{C}$ for $2 \mathrm{~h}$. An aliquot $(10 \mu \mathrm{l})$ of the extract was analyzed by photodiode-array HPLC as follows: column, Capcellpak C18 AG-120A ( $5 \mu \mathrm{m}, 4.6 \mathrm{~mm}$ I.D. $\times 250 \mathrm{~mm}$, Shiseido, Japan); solvent, $\mathrm{MeCN} / \mathrm{H}_{2} \mathrm{O}(1 \% \mathrm{AcOH})$ gradient of $15 \% \mathrm{MeCN}$ to $25 \% \mathrm{MeCN}$ in $15 \mathrm{~min}$, to $70 \% \mathrm{MeCN}$ in another $35 \mathrm{~min}$, then to $100 \%$ in $10 \mathrm{~min}$; flow rate, $1 \mathrm{ml} / \mathrm{min}$; column temp, $40^{\circ} \mathrm{C}$; detector, photodiode array SPD$\mathrm{M} 10 \mathrm{~A}_{\mathrm{VP}}$ system (Shimadzu). The quantities of constituents were determined on the basis of their peak area of UV absorption at $254 \mathrm{~nm}(\mathrm{GL}), 280 \mathrm{~nm}(\mathrm{~GB}), 292 \mathrm{~nm}$ (PN, LF), $350 \mathrm{~nm}$ (GC, IQ, RT). Each constituent was identified by 
comparison of its retention time and UV spectrum with the respective authentic sample.

\section{RESULTS}

A Field Survey of Glycyrrhiza Plants from Almaty to Tashkent A field survey of Glycyrrhiza plants was carried out on the route from Almaty (Kazakhstan) to Tashkent (Uzbekistan) in 2001, and 24 Glycyrrhiza plants were collected at the 12 habitats shown in Fig. 1. Two species, $G$. glabra and $G$. uralensis, were discriminated on the basis of phenotypic changes of their fruits: the former species having straight pods and the latter falcated ones. ${ }^{10)}$ The morphological classification of Glycyrrhiza plants collected in Kazakhstan was first attempted based on phenotypic changes of

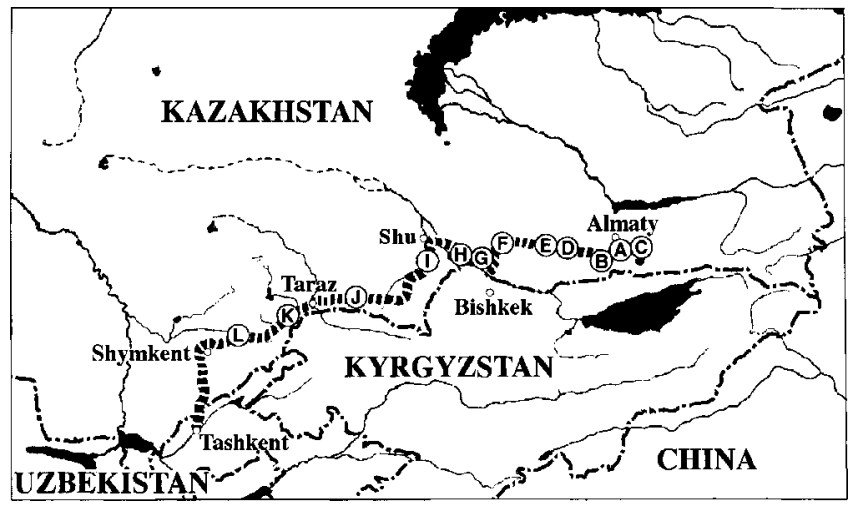

Fig. 1. Collection Sites of Glycyrrhiza Plants in Kazakhstan

A: Almaty; B: $15 \mathrm{~km}$ west of Almaty; C: $15 \mathrm{~km}$ east of Almaty; D: $2 \mathrm{~km}$ west of Samsy; E: $5 \mathrm{~km}$ west of Targan; F: $5 \mathrm{~km}$ northeast of Qurday; G: $5 \mathrm{~km}$ northwest of Qasyk; H: $5 \mathrm{~km}$ south of Blagoveshchenka; I: $20 \mathrm{~km}$ south of Shu; J: $5 \mathrm{~km}$ west of Aqyrtobe; K: $20 \mathrm{~km}$ southwest of Taraz; L: $5 \mathrm{~km}$ west of Zhaskeshu.

Table 1. Collection Sites of Glycyrrhiza Plants in the Field Survey in Kazakhstan

\begin{tabular}{|c|c|c|c|c|}
\hline Date & Collection site & Plant No. & Species & $\begin{array}{c}\text { Type of } r b c L \\
\text { sequence }\end{array}$ \\
\hline 01.08 .09 & A & $01 \mathrm{~A} 05$ & G. uralensis & n.d. ${ }^{a)}$ \\
\hline 01.08 .10 & $\mathrm{~B}$ & 01A07 & G. uralensis & n.d. \\
\hline 01.08 .10 & $\mathrm{C}$ & $01 \mathrm{~A} 10$ & G. uralensis & G-A type \\
\hline 01.08 .10 & $\mathrm{C}$ & 01A11 & Intermediate & A-T type \\
\hline 01.08 .10 & $\mathrm{C}$ & 01A12 & G. glabra & A-T type \\
\hline 01.08 .10 & $\mathrm{C}$ & $01 \mathrm{~A} 13$ & Intermediate & G-A type \\
\hline 01.08 .11 & $\mathrm{D}$ & $01 \mathrm{~A} 14$ & G. uralensis & n.d. \\
\hline 01.08 .11 & $\mathrm{E}$ & $01 \mathrm{~A} 15$ & G. uralensis & n.d. \\
\hline 01.08 .11 & $\mathrm{~F}$ & $01 \mathrm{~A} 16$ & G. glabra & n.d. \\
\hline 01.08 .11 & $\mathrm{~F}$ & $01 \mathrm{~A} 17$ & G. uralensis & n.d. \\
\hline 01.08 .11 & G & 01A18 & G. uralensis & n.d. \\
\hline 01.08 .11 & G & 01A19 & G. glabra & n.d. \\
\hline 01.08 .11 & G & 01A20 & G. glabra & n.d. \\
\hline 01.08 .11 & $\mathrm{H}$ & 01A21 & G. glabra & A-T type \\
\hline 01.08 .11 & $\mathrm{H}$ & 01A22 & G. glabra & A-T type \\
\hline 01.08 .11 & $\mathrm{H}$ & $01 \mathrm{~A} 23$ & Intermediate & G-A type \\
\hline 01.08 .11 & $\mathrm{H}$ & $01 \mathrm{~A} 24$ & Intermediate & A-T type \\
\hline 01.08 .11 & $\mathrm{H}$ & $01 \mathrm{~A} 25$ & G. uralensis & G-A type \\
\hline 01.08 .12 & I & $01 \mathrm{~A} 26$ & G. uralensis & G-A type \\
\hline 01.08 .12 & I & 01A27 & Intermediate & G-A type \\
\hline 01.08 .12 & I & 01A28 & G. glabra & A-T type \\
\hline 01.08 .12 & $\mathrm{~J}$ & 01A29 & G. glabra & n.d. \\
\hline 01.08 .12 & $\mathrm{~K}$ & 01A30 & G. glabra & n.d. \\
\hline 01.08 .13 & $\mathrm{~L}$ & 01A31 & G. glabra & n.d. \\
\hline
\end{tabular}

a) Not determined. the fruits. As shown in Table 1, G. uralensis plants were identified at 9 sites, and G. glabra at 8 sites. G. uralensis plants were exclusively observed at eastern collection sites A, B, D and E near Almaty, while only G. glabra plants were found at western collection sites $\mathrm{J}, \mathrm{K}$ and $\mathrm{L}$. At sites $\mathrm{F}, \mathrm{G}, \mathrm{H}$ and I near Bishkek, Kyrgyzstan, and site C near Almaty, $G$. glabra and G. uralensis grew together forming a mixed population. Putative intermediate-type plants between the two were also observed at sites $\mathrm{C}, \mathrm{H}$ and I. Figure 2 shows the fruits of the three types of Glycyrrhiza plants collected in Kazakhstan. The fruit of the intermediate-type plant (01A24) was slightly falcated unlike those of G. glabra (01A30) and $G$. uralensis (01A07), suggesting that this plant is an intermediate form between the two species.

Next, the shapes of leaves of G. uralensis, G. glabra and the intermediate-type plants collected at collection site $\mathrm{C}$ were compared, as shown in Fig. 3. Leaflets of plant 01A10 were ovate in shape, typical of those of $G$. uralensis, whereas those of plant 01A12 were linear-oblong, characteristic of $G$. glabra. Leaves of plants 01A11 and 01A13 were intermediate between these two species. These two intermediate-type plants could be identified as G. glabra from the shape of their legumes ${ }^{10)}$ but were different from those of typical G. glabra collected at the other sites in Kazakhstan.

It is noteworthy that a mixed population of $G$. uralensis, $G$. glabra and intermediate-type plants was observed at collection site $\mathrm{C}$ near Almaty, whereas only G. uralensis was observed at the other sites A, B, D and E near Almaty. It is sug-

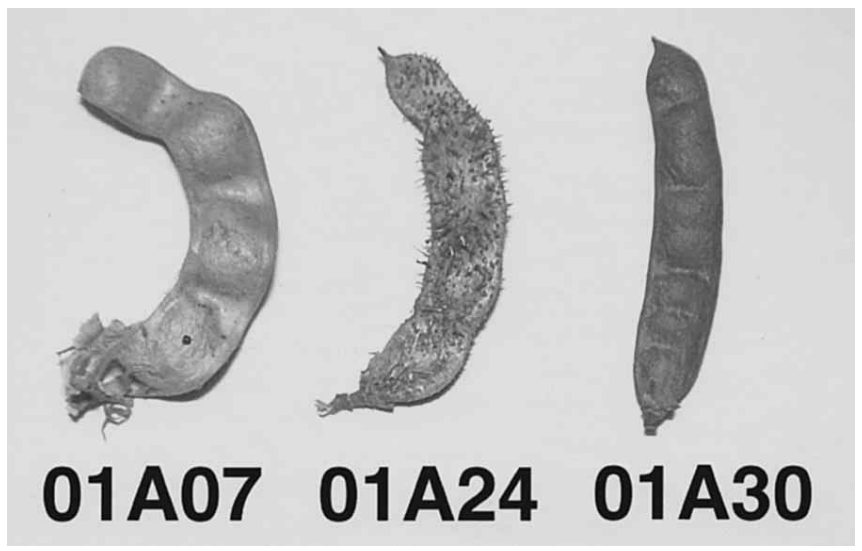

Fig. 2. Comparison of Fruits of G. uralensis (01A07), the Intermediate Plant (01A24) and G. glabra (01A30) Collected in Kazakhstan

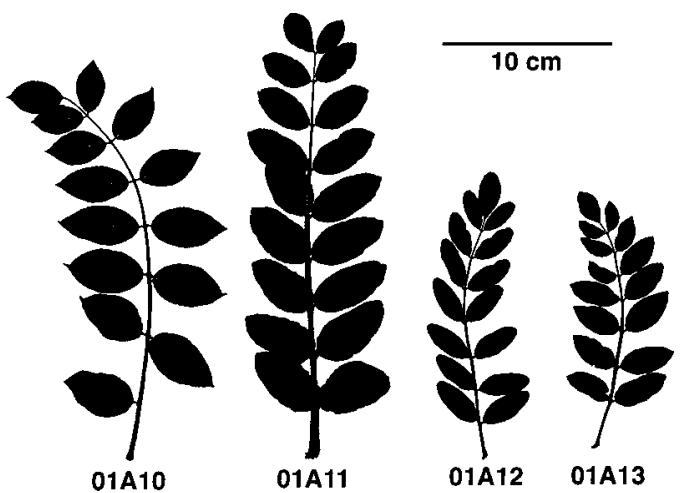

Fig. 3. Comparison of Leaves of Glycyrrhiza Plants from Collection Site C 
gested that G. glabra and the intermediate-type plants were accidentally introduced into this habitat. In contrast, the mixed population of G. glabra and G. uralensis was very common at sites F, G, H, and I. At site H, intermediate-type plants were the most common, followed by G. uralensis. Although typical G. glabra were rare at this habitat, two typical G. glabra plants, having echinulate fruits (01A21) or fruits without echines (01A22), were collected.

It is also noteworthy that the germination rate of seeds from the intermediate plant (01A27) collected at site I was high $(70 \%)$, whereas those from other intermediates at collection sites $\mathrm{C}$ and $\mathrm{H}$ were low. It is of interest to elucidate the characteristics of the descendants of these intermediatetype plants, which might be important sources for breeding of Glycyrrhiza plants.

Comparison of Chloroplast $r b c L$ Sequence In our previous work $^{6)}$ we determined the nucleotide sequences of a chloroplast gene for the large subunit of ribulose-1,5-bisphosphate carboxylase/oxygenase $(r b c L)$ of Glycyrrhiza plants to elucidate their phylogenetic relationship. Two nucleotide substitutions (in 1324 nucleotides) were observed between the $r b c L$ gene sequences of G. glabra (A-T type) and $G$. uralensis (G-A type). Thus, the $r b c L$ sequence determination might be useful for characterization of the intermediate-type plants collected in Kazakhstan.

DNA was isolated from dry leaves of Glycyrrhiza plants collected at sites $\mathrm{C}, \mathrm{H}$ and $\mathrm{I}$, where the intermediate-type plants were collected together with G. glabra and G. uralensis. The 240-bp DNA fragment covering the two nucleotide substitutions in the $r b c L$ gene was amplified by PCR and sequenced. As shown in Table 1, the rbcL genes for G. glabra plants, having linear-oblong leaflets and straight fruits, from the three collection sites were identified as the A-T type sequence ( $G$. glabra-type), and those of G. uralensis plants, having ovate leaflets and falcated fruits, were the G-A type sequence (G. uralensis-type). These are in accordance with our previous results. ${ }^{6}$ Interestingly, $r b c L$ genes of the intermediate-type plants were divided into G. glabra-type and $G$.

Table 2. Content of Glycyrrhizin (GL), Glabridin (GB) and Glycycoumarin (GC) in Underground Parts of Glycyrrhiza Plants Collected in Kazakhstan

\begin{tabular}{|c|c|c|c|c|c|c|c|}
\hline \multirow{2}{*}{ Site } & \multirow{2}{*}{$\begin{array}{l}\text { Plant } \\
\text { No. }\end{array}$} & \multirow{2}{*}{ Species } & \multirow{2}{*}{ Root/Stolon } & \multirow{2}{*}{$\begin{array}{l}\text { Diameter } \\
(\mathrm{mm})\end{array}$} & \multicolumn{3}{|c|}{ Content ( $\%$ of dry weight) } \\
\hline & & & & & GL & GB & GC \\
\hline $\mathrm{B}$ & 01A07 & G. uralensis & Root & 23.0 & 3.55 & n.d. ${ }^{a)}$ & 0.07 \\
\hline $\mathrm{C}$ & $01 \mathrm{~A} 10$ & G. uralensis & Stolon & 6.5 & 5.57 & n.d. & 0.20 \\
\hline $\mathrm{C}$ & $01 \mathrm{~A} 11$ & Intermediate & Stolon & 6.7 & 5.28 & n.d. & n.d. \\
\hline $\mathrm{C}$ & $01 \mathrm{~A} 12$ & G. glabra & Stolon & 6.9 & 2.14 & 0.28 & n.d. \\
\hline $\mathrm{C}$ & $01 \mathrm{~A} 13$ & Intermediate & Stolon & 8.0 & 3.69 & n.d. & n.d. \\
\hline $\mathrm{H}$ & $01 \mathrm{~A} 24$ & Intermediate & Root & 14.5 & 5.72 & n.d. & n.d. \\
\hline K & 01A30 & G. glabra & Stolon & 5.4 & 2.16 & 0.34 & n.d. \\
\hline
\end{tabular}

a) Not detected (including not identified by UV spectrum).

Table 3. Contents of Rutin (RT), Isoquercitrin (IQ), Pinocembrin (PN), Licoflavanone (LF) and Two Unidentified Compounds $(1,2)$ in the Leaves of Glycyrrhiza Plants Collected in Kazakhstan

\begin{tabular}{|c|c|c|c|c|c|c|c|c|}
\hline \multirow{2}{*}{ Species } & \multirow{2}{*}{ Site } & \multirow{2}{*}{$\begin{array}{l}\text { Plant } \\
\text { No. }\end{array}$} & \multicolumn{4}{|c|}{ Content ( $\%$ of dry weight) } & \multicolumn{2}{|c|}{ Relative ratio of peak area ${ }^{a}$} \\
\hline & & & RT & IQ & $\mathrm{PN}$ & LF & 1 & 2 \\
\hline \multirow[t]{9}{*}{ G. uralensis } & A & $01 \mathrm{~A} 05$ & 0.11 & 0.19 & n.d. ${ }^{b)}$ & n.d. & 100 & 55 \\
\hline & B & 01A07 & 0.09 & 0.37 & n.d. & n.d. & 38 & 14 \\
\hline & $\mathrm{C}$ & 01A 10 & 0.06 & 0.13 & n.d. & n.d. & 56 & 41 \\
\hline & $\mathrm{D}$ & $01 \mathrm{~A} 14$ & 0.13 & 0.52 & n.d. & n.d. & 43 & 18 \\
\hline & $\mathrm{E}$ & $01 \mathrm{~A} 15$ & 0.10 & 0.37 & n.d. & n.d. & 68 & 29 \\
\hline & $\mathrm{F}$ & 01A 17 & 0.12 & 0.45 & n.d. & n.d. & 44 & 16 \\
\hline & $\mathrm{G}$ & 01A18 & 0.12 & 0.46 & n.d. & n.d. & 204 & 110 \\
\hline & $\mathrm{H}$ & $01 \mathrm{~A} 25$ & 0.14 & 0.43 & n.d. & n.d. & 112 & 117 \\
\hline & I & 01A26 & 0.10 & 0.23 & n.d. & n.d. & 185 & 114 \\
\hline \multirow{5}{*}{$\begin{array}{l}\text { Intermediate- } \\
\text { Plants }\end{array}$} & $\mathrm{C}$ & 01A11 & 0.40 & 0.05 & 0.24 & 0.28 & 8 & 1 \\
\hline & $\mathrm{C}$ & $01 \mathrm{~A} 13$ & 0.39 & 0.05 & 0.04 & 0.07 & 33 & 37 \\
\hline & $\mathrm{H}$ & $01 \mathrm{~A} 23$ & 0.55 & 0.07 & 0.15 & 0.22 & 11 & 9 \\
\hline & $\mathrm{H}$ & 01A24 & 0.58 & 0.08 & 0.15 & 0.18 & 19 & 20 \\
\hline & I & $01 \mathrm{~A} 27$ & 0.26 & 0.04 & 0.18 & 0.29 & 17 & 18 \\
\hline \multirow[t]{10}{*}{ G. glabra } & $\mathrm{C}$ & 01A12 & 0.34 & 0.05 & 2.30 & 0.50 & n.d. & n.d. \\
\hline & $\mathrm{F}$ & $01 \mathrm{~A} 16$ & 0.44 & 0.03 & 1.93 & 0.59 & n.d. & n.d. \\
\hline & G & 01A19 & 0.34 & 0.02 & 1.64 & 0.24 & n.d. & n.d. \\
\hline & G & 01A20 & 0.35 & 0.05 & 1.01 & 0.26 & n.d. & n.d. \\
\hline & $\mathrm{H}$ & $01 \mathrm{~A} 21$ & 0.60 & 0.05 & 1.19 & 0.27 & n.d. & n.d. \\
\hline & $\mathrm{H}$ & 01A22 & 0.66 & 0.04 & 2.41 & 0.20 & n.d. & n.d. \\
\hline & I & 01A28 & 0.51 & 0.03 & 1.22 & 0.17 & n.d. & n.d. \\
\hline & $\mathrm{J}$ & 01A29 & 0.33 & 0.02 & 1.46 & 0.17 & n.d. & n.d. \\
\hline & K & 01A30 & 0.75 & 0.04 & 0.82 & 0.26 & n.d. & n.d. \\
\hline & $\mathrm{L}$ & 01A31 & 0.46 & 0.03 & 1.43 & 0.28 & n.d. & n.d. \\
\hline
\end{tabular}


uralensis-type. These results, coupled with the fact that chloroplast genes including $r b c L$ gene arise from their female ancestors, suggest that the G. glabra-type (01A11 and $01 \mathrm{~A} 24)$ and the G. uralensis-type (01A13, 01A23 and 01A27) of the intermediate-type plants are derived from the female ancestors of G. glabra and G. uralensis, respectively.

HPLC Analysis of GL and Species-Specific Flavonoids in Underground Parts Since a sweet saponin, GL, and species-specific flavonoids, GB for G. glabra and GC for $G$. uralensis, were important index compounds for the underground parts of licorice, photodiode-array HPLC analysis was performed to determine the contents of GL, GB and GC in the roots and stolons collected in the present survey. Table 2 shows these contents in the roots and stolons collected in habitats $\mathrm{B}, \mathrm{C}, \mathrm{H}$, and $\mathrm{K}$; the GL contents were found to vary from 2.14 to $5.72 \%$ of dry weight, depending on the sample. On the other hand, the species-specific flavonoids, GB and $\mathrm{GC}$, were detected in the underground parts of G. glabra and G. uralensis, respectively, but neither flavonoid was detected in the underground parts of the intermediate-type plants (01A11, 01A13, and 01A24).

HPLC Analysis of Flavonoids in Leaves Variations in the flavonoid content were reported in the leaves of Glycyrrhiza plants, ${ }^{3,6,8,9)}$ and these differences in flavonoid composition might serve as a good marker to determine the species and strain of the plants. Thus, a photodiode-array HPLC analysis was performed to compare the HPLC profile of the leaves collected in this survey. As shown in Table 3, the HPLC profiles of leaf extracts from the 24 plants were divided into three groups: G. uralensis-type, G. glabra-type and their intermediate-type. Figure 4 shows the structures of two flavonol glycosides (RT and IQ) and two flavanones (PN and LF), which were identified by comparison of their HPLC behavior and UV spectra with those of the authentic samples. Typical HPLC profiles for G. uralensis, G. glabra and the intermediate plants are shown in Fig. 5.

In the HPLC profile of all G. uralensis plants, IQ at $11.6 \mathrm{~min}$ was detected as the major flavonol glycoside, and two major unidentified peaks at $25.9 \mathrm{~min}$ and $35.3 \mathrm{~min}$ were observed. It is noteworthy that the HPLC profile of $G$. uralensis leaves collected in the present study was different from that of $G$. uralensis leaves reported in our previous paper, ${ }^{6}$ which used a G. uralensis plant from China, suggesting that the flavonoid composition was also different among the various strains of this species.

In the HPLC profile of all G. glabra plants, RT at $10.4 \mathrm{~min}$ was detected as the major flavonol glycoside, unlike the case of G. uralensis plants. In addition, two flavanones, PN at $36.9 \mathrm{~min}$ and $\mathrm{LF}$ at $41.5 \mathrm{~min}$, were identified by comparison with the reference samples in their retention times and UV spectra. Although these flavanones were also detected in the leaves of G. glabra collected in Turkey, Italy and Spain, ${ }^{8,15,16)}$ the major leaf flavonoid glycoside of G. glabra in these three countries was not RT but IQ, as observed in G. uralensis leaves in Kazakhstan. This difference might be a marker discriminating the origin of G. glabra. It is also noteworthy that no significant difference in the HPLC profiles was observed between the two types based on the absence (01A12, 01A16, 01A $19,01 \mathrm{~A} 22,01 \mathrm{~A} 28,01 \mathrm{~A} 29,01 \mathrm{~A} 30)$ or presence (01A20, 01A21, 01A31) of echines on the fruits.

In contrast, the major flavonoid glycoside in the leaves of

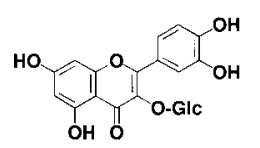

Isoquercitrin (IQ)

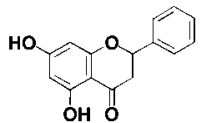

Pinocembrin (PN)

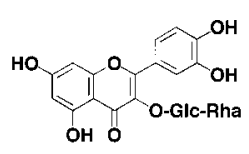

Rutin (RT)

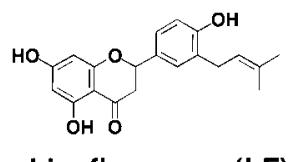

Licoflavanone (LF)
Fig. 4. Structures of Flavonol Glycosides (RT, IQ) and Flavanones (PN, LF) in the Leaves of Glycyrrhiza Plants
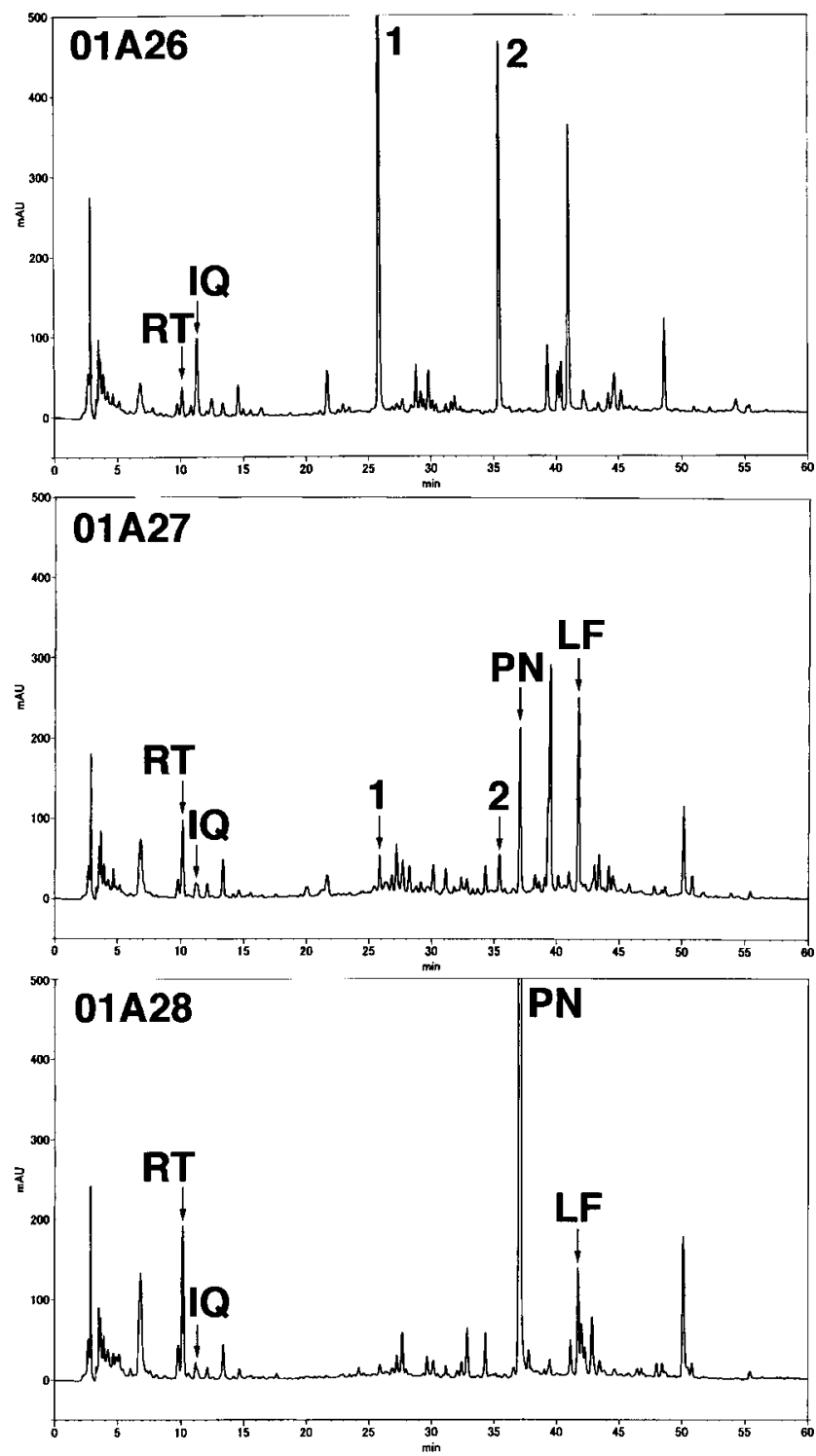

Fig. 5. HPLC Profiles of Methanol Extracts of Leaves of G. uralensis (01A26), the Intermediate Plant (01A27) and G. glabra (01A28) at Collection Site I

Absorbance at $292 \mathrm{~nm}$. RT, rutin; IQ, isoquercitrin; PN, pinocembrin; LF, licoflavanone, 1 and 2 , unidentified.

the intermediate plants was RT, as in G. glabra leaves. Interestingly, however, PN and LF, two flavanones characteristic of G. glabra leaves, together with two unidentified ones, 1 and 2 in G. uralensis leaves, were detected in the leaves of all 
intermediate plants, although differing in their content. This result also suggests that the intermediate plants are hybrids of G. glabra and G. uralensis.

\section{DISCUSSION}

The present study showed that Glycyrrhiza plants collected in Kazakhstan could be divided into three groups: $G$. uralensis-type, G. glabra-type and the intermediate-type, by comparison of their morphological characteristics and HPLC profiles of their underground parts and leaves. It is noteworthy that G. uralensis, G. glabra and the intermediate plants grew together forming a mixed population at the three collection sites $\mathrm{C}, \mathrm{H}$ and I. Although the morphological characteristics and the HPLC profiles are similar among various intermediate-plants collected in this study, the chloroplast $r b c L$ genes of the intermediate-plants were divided into G. glabratype and G. uralensis-type, suggesting that the female ancestors of these types were G. glabra and G. uralensis, respectively. These results suggest that the intermediate plants are hybrids of G. uralensis and G. glabra, which form a mixed population in this region, although further studies are necessary to confirm this hypothesis.

It is interesting that the underground parts of the intermediate plants contain neither GB nor GC, which are known as species-specific flavonoids for G. glabra and G. uralensis, respectively. It was previously reported that Glycyrrhiza plants collected in northwestern China, which were identified as $G$. glabra from their morphological characteristics, do not contain G. glabra-specific GB. ${ }^{17)}$ At collection site H, the intermediate plants were the most common, and it was very difficult to find a typical G. glabra. Based on the similarity of the morphological characteristics between G. glabra and the intermediate plants, the latter would be classified as G. glabra. Thus, the G. glabra plants in the above-mentioned report ${ }^{17}$ were suggested to be the intermediate-plants observed here. In contrast to the species-specific flavonoids of the roots, both G. glabra-specific and G. uralensis-specific constituents were detected in the HPLC experiments on the leaves of the intermediate plants, although many index compounds common to G. uralensis and the intermediate plants have not yet been identified. Characterization of these index compounds from the leaves, which is important in determining the difference among the three types of Glycyrrhiza plants in Kazakhstan, is underway.

Acknowledgments This work was supported in part by a Grant-in-Aid for Scientific Research (No. 12576027) from the Ministry of Education, Science, Sports, Culture and Technology, Japan. The authors would like to thank Mr. Y. Tamura (Maruzen Pharmaceuticals) for providing authentic samples for GL, GB and GC.

\section{REFERENCES AND NOTES}

1) Gibson M. R., J. Nat. Prod., 41, 348-354 (1978).

2) Shibata S., Yakugaku Zasshi, 120, 849-862 (2000).

3) Nomura T., Fukai T., "Progress in the Chemistry of Organic Natural Products," 73, ed. by Herz W., Kirby G. W., Moore R. E., Steglich W., Tamm C., Springer, Wien-New York, 1998, pp. 1-140.

4) Shibata S., Saitoh T., J. Indian Chem. Soc., 55, 1184-1191 (1978).

5) Hatano T., Fukuda T., Liu Y. Z., Noro T., Okuda T., Yakugaku Zasshi, 111, 311-321 (1991).

6) Hayashi H., Hosono N., Kondo M., Hiraoka N., Ikeshiro Y., Shibano M., Kusano G., Yamamoto H., Tanaka T., Inoue K., Biol. Pharm. Bull., 23, 602-606 (2000).

7) Zeng L., Lou Z. C., Zhang R. Y., Acta Pharmaceutica Sinica, 26, 788 - 793 (1991)

8) Hayashi H., Yasuma M., Hiraoka N., Ikeshiro Y., Yamamoto H., Yesilada E., Sezik E., Honda G., Tabata M., Phytochemistry, 42, 701-704 (1996).

9) Shibano M., Matsumoto Y., Kusano G., Shibata T., Natural Medicines, 50, 273-283 (1996).

10) Grigor'ev Y. S., Vasil'chenko I. T. "Flora of the USSR," Vol. 12, ed. by Shishkin B. K., Academy of Sciences of the USSR, Moscow, 1946, pp. $230-239$.

11) Zeng L., Li S. H., Lou Z. C., Acta Pharmaceutica Sinica, 23, 200208 (1988)

12) Ashurmetov O. A., Genet. Resour. Crop Ev., 43, 167-171 (1996).

13) Fukui H., Goto K., Tabata M., Chem. Pharm. Bull., 36, 4174-4176 (1988).

14) Murray M. G., Thompson W. F., Nucleic Acids Res., 8, 4321—4325 (1980).

15) Hayashi H., Honda G., Tabata M., Yamamoto H., Natural Medicines, 49, 129-132 (1995).

16) Hayashi H., Shibano M., Kusano G., Yamamoto H., Ikeshiro Y., Natural Medicines, 52, 259-264 (1998).

17) Kitagawa I., Chen W., Hori K., Harada E., Yasuda N., Yoshikawa M., Ren J., Chem. Pharm. Bull., 42, 1056-1062 (1994). 